\title{
POST-COMBUSTION EVOLUTION OF SOOT PROPERTIES IN AN AIRCRAFT ENGINE
}

\author{
Pierre M. Dakhel, Stephen P. Lukachko \\ and Ian A. Waitz \\ Massachusetts Institute of Technology \\ 77 Massachusetts Avenue \\ Cambridge MA, 02139
}

\author{
Richard C. Miake-Lye and Robert C. Brown \\ Aerodyne Research, Inc. \\ 45 Manning Road \\ Billerica MA, 01821
}

\begin{abstract}
Recent measurements have suggested that soot properties can evolve downstream of the combustor, changing the characteristics of aviation particulate matter (PM) emissions and possibly altering the subsequent atmospheric impacts. This paper addresses the potential for the post-combustion thermodynamic environment to influence aircraft non-volatile PM emissions. Microphysical processes and interactions with gas phase species have been modeled for temperatures and pressures representative of in-service engines. Time-scale arguments are used to evaluate the relative contributions that various phenomena may make to the evolution of soot, including coagulation growth, ion-soot attachment, and vapor condensation. Then a higher-fidelity microphysics kinetic is employed to estimate the extent to which soot properties evolve as a result of these processes. Results suggest that limited opportunities exist for the modification of the size distribution of the soot, its charge distribution, or its volatile content, leading to the conclusion that the characteristics of the turbine and nozzle of an aircraft engine have little or no influence on aircraft non-volatile emissions. Combustor processing determines the properties of soot particulate matter emissions from aircraft engines, setting the stage for interactions with gaseous emissions and development as cloud condensation nuclei in the exhaust plume.
\end{abstract}

Keywords: particulate matter, soot, emissions, microphysics, ions

\section{INTRODUCTION}

Aircraft emissions can affect the health and welfare of people living in the neighborhood of airports through changes in air quality, and can also influence climate. An accurate description of the chemical state of the engine exhaust is a necessary prerequisite to assessing the extent of these effects. Exhaust characterization must include the full range of aircraft operating conditions, from ground to flight altitude, and consider the evolution of thermodynamic conditions along a path that includes the intra-engine environment as well as the exhaust plume. Understanding how the chemistry and physics of aircraft particulate matter (PM) develop along this path is a necessary step towards alleviating potential impacts. Recent measurements have suggested that soot properties can evolve within an aircraft engine, altering the characteristics of the emitted PM [1,2]. This paper addresses the potential for the post-combustion thermodynamic environment to influence aircraft non-volatile, carbonaceous PM emissions.

Measurements have demonstrated that exhaust gases and water vapor condense on emitted non-volatile particles in the exhaust plume $[3,4]$. This can change the tendency for nonvolatile PM to act as cloud condensation nuclei and alter their role in contrail formation. Radiative forcing resulting from contrail and cirrus cloud formation has been indicated by measurements [5] and the cumulative magnitude of the effect to date is estimated to be roughly equivalent to that of carbon dioxide emissions from aviation [6-11]. Heterogeneous processing may also influence the chemical composition of aircraft soot emissions with potential toxicological consequences. It is currently unknown whether non-volatile, carbonaceous PM should be classified as a hazardous air pollutant (HAP) [12]. Apart from the classification of the soot itself, it is also possible that the soot could absorb or act as a condensation site for other emitted HAPs.

Since condensation on non-volatile PM is partly controlled by the particle size distribution, it is important to understand the potential for coagulation growth within and downstream of the engine. Understanding differences in non-volatile particle properties at the combustor exit relative to their subsequent state at the engine exit may also improve the combustor development process. As measurement capabilities for determining particle emissions are matured and implemented, knowing that the com- 
bustor exit plane is a viable alternative measurement location to the engine exit plane can save considerable expense in sampling.

Experimental programs, including the NASA-QinetiQ Collaborative Program [1] and the European Union PartEmis project [2], have begun to investigate potential modification of soot properties through the engine turbine and exhaust nozzle. A limited number of these measurements show significant changes in the non-volatile size distribution and the presence of volatile condensate on the soot. Whitefield et al. [1] report a $3 \mathrm{~nm}$ $(\sim 10 \%)$ growth in particle mean diameter. This increase may indicate that intra-engine thermodynamic conditions are favorable for coagulation or condensation. Petzold et al. [2] also measure an increase in the mean diameter, but attributed the change to variability in engine operating point between experiments rather than an active microphysical process. In addition, Petzold et al. [2] detected a volatile coating on soot particles at the engine exit that was not evident on particles at combustor exit.

These different interpretations of the measured particle growth were one impetus for the model development and analysis of this study. While we treat the intra-engine environment specifically, it is important to note that results developed through both the NASA-QinetiQ and PartEmis programs were perhaps confounded by the possibility of additional heterogeneous processing within the particulate measurement systems themselves. There is a strong modification in the pressure and temperature environment experienced by the particle after entering the sampling probe. This is coupled with a time-scale within the apparatus that is longer than the absolute age of the soot particle at the time it enters the probe.

Exhaust chemistry depends on fuel type, the thermodynamic environment within the engine and in the plume (as driven by cycle, component design, and ambient atmospheric conditions), and also the residence time in any one of these environments, stretching from milliseconds in the combustor and the turbine, to minutes in the plume and days in the subsequent atmospheric processing. To facilitate study of this system from the standpoint of emissions characterization, it is convenient to examine the evolution of the aircraft exhaust in three regions, combustor, turbine-nozzle, and plume. Each region corresponds to a particular thermodynamic environment with a characteristic timescale and hence, emphasizes different aspects of the chemistry.

This study employs numerical models and time-scale analyses to explore the potential for soot particle growth via agglomeration, particle scavenging, and vapor condensation in the engine turbine and nozzle. Several studies have addressed the evolution of the chemical state of the flow through the turbine and nozzle of an aircraft engine [13-19]. These investigations have shown the unique role of gas phase chemistry along the postcombustion flow path in the production of sulfate and nitrate aerosol precursors. Little is known about the evolution of nonvolatile PM through this same environment. Estimates of precursor emissions suggest that non-volatile particulate emissions constitute a major fraction of the total particulate mass found in the near-field plume ( $\sim 1 \mathrm{~s}$ after emission) [19]. Soot is the only component of the overall PM mass present at these times that has nucleated and developed by the combustor exit and is the dominant contributor to aircraft engine non-volatile emissions, representing virtually all the non-volatile particle mass.
Rates for the microphysical processes that govern the evolution of non-volatile PM can be determined with the knowledge of the temperature and pressure of the surrounding environment and the initial chemical composition of the fluid. After formation in the primary zone of the combustor, soot particles undergo rapid coagulation and surface growth, and are cooled through the addition of dilution air in the combustor aft section. By the time particles arrive at the turbine inlet, their mean age is on the order of 3-8 ms and they are at a temperature 500-1000 $\mathrm{K}$ lower than at nucleation. At ground level, the particles undergo a fast expansion through the turbine and nozzle from pressures as high as $40 \mathrm{~atm}$ for in-service engines to atmospheric pressure within 1-3 ms. The flow is also diluted by the addition of turbine cooling air early in the gas path (cooling can be responsible for more than $20 \%$ of the mass flow) and later again in the nozzle for engines with internal core-bypass mixing. This paper is organized to provide a step-by-step description of the analysis of this intra-engine system. In Section 1 we examine the evolution of the soot size distribution due to coagulation between neutral particles. Section 2 deals with the charge distribution and its effect on the coagulation. Section 3 summarizes conclusions from our evaluation of the potential for non-volatile particulate matter processing in the post-combustor flow path within a gas turbine engine.

\section{COAGULATION}

In this section we consider coagulation as a means for particle growth within the engine. Three types of coagulation have been considered: Brownian coagulation, turbulent shear coagulation, and turbulent inertial coagulation. In most flows and for most particle types, Brownian coagulation is dominant. However, since the flow in an aircraft turbine is strongly turbulent, it was not clear at the outset whether the two latter types of coagulation would be negligible within the engine. A bounding analysis shows this to be the case for turbomachinery flows and the particle size ranges expected in an aircraft engine. The evaluation also suggests that any intra-engine coagulation that occurs will be confined to the combustor.

We first examine characteristic time-scales for coagulation to assess whether there is enough time within the engine for such processing to occur. Characteristic time-scales are estimated as $2 /\left(\mathrm{K}_{\mathrm{c}} \cdot \mathrm{N}_{0}\right)$, where $\mathrm{N}_{0}$ is the particle number density at the beginning of the coagulation process and $\mathrm{K}_{\mathrm{c}}$ is the coagulation kernel. The coagulation kernel is the equivalent of a chemical reaction rate parameter. The nomenclature differs simply to reflect the non-chemical nature of the process but it refers to the same concept.

Strictly, coagulation time-scales are properly defined only for monodisperse distributions, but we still can define the timescale here as an upper bound for the time necessary to decrease the particle number density by a factor of 2 . Soot radii between $5 \mathrm{~nm}$ and $50 \mathrm{~nm}$ were considered, matching the range found in existing measurements of non-volatile particulate emissions from aircraft engines [20-27].

To estimate $\mathrm{N}_{0}$, further specification of soot properties such as the mass emission index and the size distribution is required. At the combustor exit of aircraft engines, soot has been measured to be log-normally distributed in a single mode (e.g. [1]). For this analysis, we assess an upper bound on the amount of coagulation that may occur using a large central size and geo- 
metric standard deviation. Coagulation kinetics are driven by $\mathrm{N}_{0}$. The total mass of non-volatile PM is specified using an emission index for soot, EIPM $_{\mathrm{nv}}$, of $1 \mathrm{~g} / \mathrm{kg}$-fuel. This is likely on the high end for the range of engines in service. Assuming a soot density between $1500-1800 \mathrm{~kg} / \mathrm{m}^{3}$, and using lognormal parameters suggested by measurements [20-27] — median radius in the range $10-30 \mathrm{~nm}$, geometric standard deviation 1.5-1.75, and number EI of $0.1 \mathrm{E} 15-6 \mathrm{E} 15$ particles $/ \mathrm{kg}$-fuel - data suggest $\mathrm{EIPM}_{\mathrm{nv}}$ is in the range $0.002-2 \mathrm{~g} / \mathrm{kg}$-fuel. For this study, the lognormal distribution of this mass is specified by a median radius of $23 \mathrm{~nm}$ and a geometric standard deviation of 1.75. Both of these values are on the high end of the range suggested by existing measurements. The choice of a large emission index and particle size is meant to put the system in a worst-case scenario for kinetics. The mass density of the soot was assumed at 1.5 $\mathrm{g} / \mathrm{cm}^{3}$. Integrated, the reference distribution equates to a number density of soot particles in the range $3 \mathrm{E} 8-5 \mathrm{E} 8 / \mathrm{cm}^{3}$ at combustor exit conditions that will be used as $\mathrm{N}_{0}$.

Coagulation kernels can be rigorously derived for spherical particles, which is an assumption we are making for aircraft soot. However, the morphology of aircraft soot is still an area of active research. Other kinds of soot particles, such as those created by automobiles, would poorly fit into such a model. Knowledge of temperature and pressure is sufficient to compute the coagulation kernel. The Brownian coagulation kernel is computed according to Fuchs [28] as given in Eq. (1) for two colliding particles.

$$
K_{c_{b r}}=\frac{4 \pi\left(r_{1}+r_{2}\right)\left(D_{1}+D_{2}\right)}{\frac{r_{1}+r_{2}}{r_{1}+r_{2}+\sqrt{\delta_{1}^{2}+\delta_{2}^{2}}}+\frac{4\left(D_{1}+D_{2}\right)}{\beta \sqrt{c_{1}^{2}+c_{2}^{2}}\left(r_{1}+r_{2}\right)}}
$$

In Eq. (1), $r$ is the particle radius and $\delta$ is the final mean free path distance between the 2 particles just before their collision as derived by Fuchs [28] and shown in Eq. (2). In Eq. (2), $\lambda_{\mathrm{a}}$ is the apparent mean free path of the particle in the carrier gas as given by Eq. (3).

$$
\begin{aligned}
& \delta=\frac{1}{6 r \lambda_{a}}\left[\left(\left(2 r+\lambda_{a}\right)^{3}-\left(4 r^{2}+\lambda_{a}^{2}\right)^{3 / 2}\right)-2 r\right] \\
& \lambda_{a}=\frac{k T C_{c}}{3 \pi c \mu r}
\end{aligned}
$$

Referring to Eq. (1), $c$ is the particle mean speed as given in Eq. (4), where $m$ is the particle mass, and $D$ is the particle diffusivity as in Eq. (5), where $C_{c}$ is an empirically derived function as given in Eq. (6).

$$
\begin{aligned}
& c=\left(\frac{8 k T}{\pi m}\right)^{1 / 2} \\
& D=\frac{k T C_{c}}{6 \pi \mu r}
\end{aligned}
$$

$$
C_{c}=1+\frac{\lambda}{r}\left[1.257+0.4 e^{\frac{1.1 .1 r}{\lambda}}\right]
$$

In Eq. (6), $C_{c}$ corrects for the non-continuum effects at low gas densities and small particle radius [29]. In Eq. (6), $\lambda$ is the mean free path of the carrier gas as given in Eq. (7), where $\mu$ is the dynamic viscosity of air given by Sutherland's law given in Eq. (8).

$$
\begin{aligned}
& \lambda=\frac{2 \mu}{P\left(\frac{8 M}{\pi R T}\right)^{1 / 2}} \\
& \mu=1.7894 .10^{-5}\left(\frac{\mathrm{T}}{273.11}\right)^{3 / 2} \frac{273.11+110.56}{\mathrm{~T}+110.56}
\end{aligned}
$$

Referring back to Eq. (1), $\beta$ is the sticking probability, the probability that a collision will result in coagulation, and it is set to one in the rest of this analysis to correspond to an upper-bound scenario.

The turbulent shear coagulation kernel was calculated according to Saffman and Turner [30] as given in Eq. (9).

$$
K_{c_{s h t}}=1.3\left(r_{1}+r_{2}\right)^{3}\left(\frac{\varepsilon}{v}\right)^{1 / 2}
$$

In Eq. (9), $v$ is the kinematic viscosity and $\varepsilon$ is the dissipation rate, here approximated by the turbulence scaling law given in Eq. (10),

$$
\varepsilon=\frac{(\mathrm{rms} \mathrm{U})^{3}}{\mathrm{~L}}
$$

In Eq. (10), $U$ is the mean speed of the flow, $L$ is the characteristic length scale for turbulent eddies, and $r m s$ is the root mean square turbulent intensity. To evaluate a maximum value for $\varepsilon$, we took $U$ at $600 \mathrm{~m}-\mathrm{s}^{-1}$, approximately Mach 1 at engine nozzle exit temperatures, $L$ at a typical blade thickness of $1 \mathrm{~cm}$, and the rms of the turbulence at $20 \%$ based on the measurements in Goebel [31].

The turbulent inertial coagulation kernel was estimated according to Pruppacher and Klett [32] as given in Eq. (11).

$$
K_{c_{i n}}=5.7\left(r_{1}+r_{2}\right)^{2}\left|\frac{C_{c_{1}} m_{1}}{6 \pi \mu r_{1}}-\frac{C_{c_{2}} m_{2}}{6 \pi \mu r_{2}}\right|\left(\frac{\varepsilon^{3}}{v}\right)^{1 / 4}
$$

Computations of the three coagulation kernels-Eqs. (1), (9), (11)-can be found in Figures 1 to 5. These figures show the pressure-temperature dependence at fixed radius and the radiusradius dependence at fixed temperature and pressure of the three coagulation kernels. To examine the pressure-temperature dependence we fix the radii of the 2 colliding particles at the median radius of the distribution, $23 \mathrm{~nm}$, and let the tempera- 
ture and pressure vary from 300 to $1900 \mathrm{~K}$ and 0.5 to $37 \mathrm{~atm}$ respectively. For the radius-radius dependence we fix the temperature and pressure at respectively $900 \mathrm{~K}$ and $10 \mathrm{~atm}$ and let the radii of the 2 colliding particles vary from 5 to $50 \mathrm{~nm}$.

Coagulation time-scales based on these estimates for $\mathrm{K}_{\mathrm{c}}$ shown in Table 1 are 2 orders of magnitude larger than the residence times through the post-combustor flow path at the combustor exit. The conclusion is that there is little opportunity for coagulation through the turbine and exhaust nozzle, particularly since we have assumed a worst-case scenario for the kinetics. Note that a characteristic time-scale cannot be defined for turbulent inertial coagulation since it is by definition infinite for particles having the same radius. Thus, to assess the importance of turbulent inertial coagulation, compare the kernel values in Figures 2 and 5 and note they are of similar magnitude.

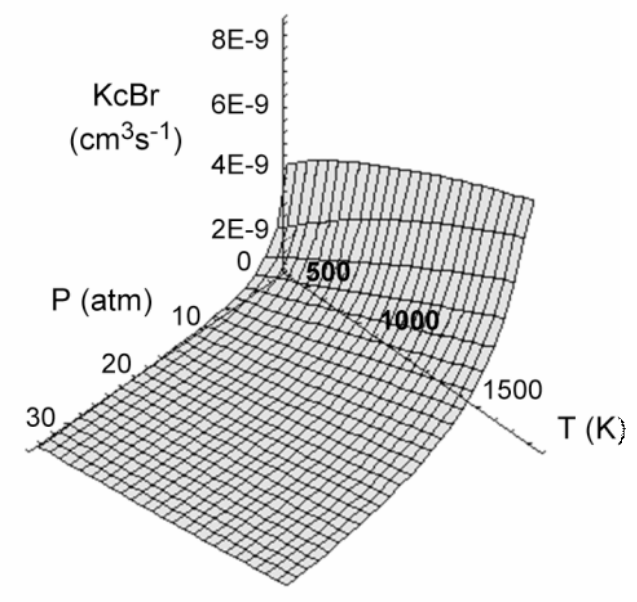

Figure 1. P-T dependence of Brownian coagulation kernel for two particles each with a $23 \mathrm{~nm}$ radius.

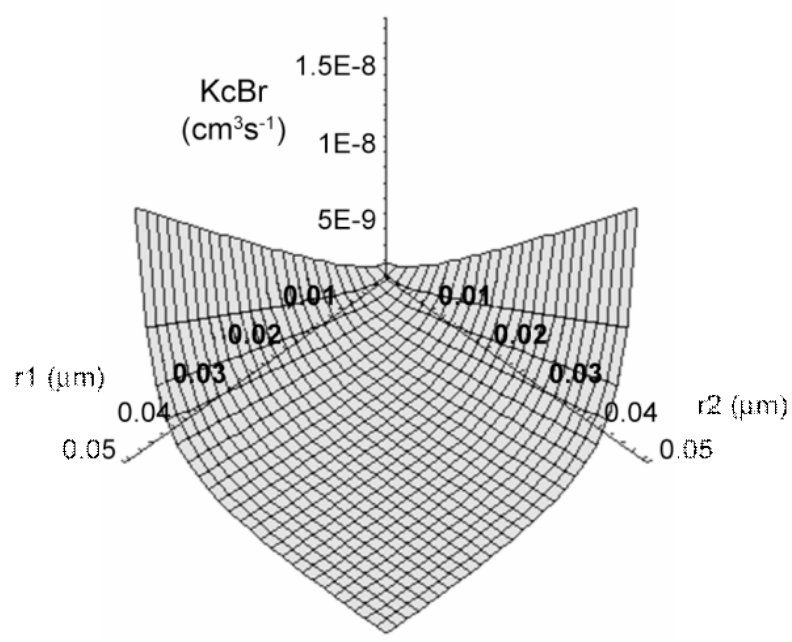

Figure 2. Radius-radius dependence of Brownian coagulation kernel at $10 \mathrm{~atm}$ and $900 \mathrm{~K}$.

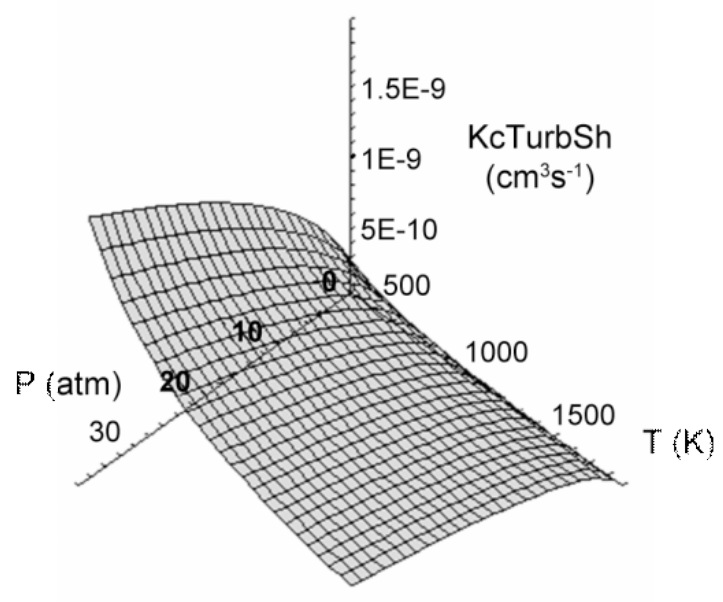

Figure 3. P-T dependence of turbulent shear coagulation kernel for two particles each with a $23 \mathrm{~nm}$ radius.

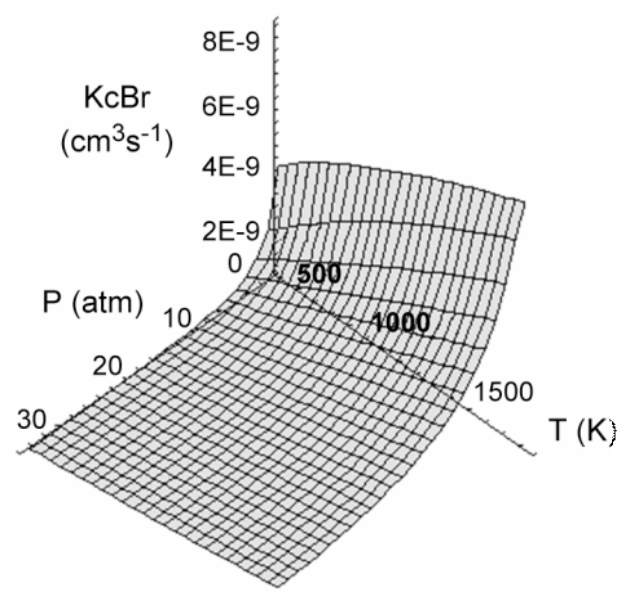

Figure 4. Radius-radius dependence of turbulent shear coagulation kernel at $10 \mathrm{~atm}$ and $900 \mathrm{~K}$.

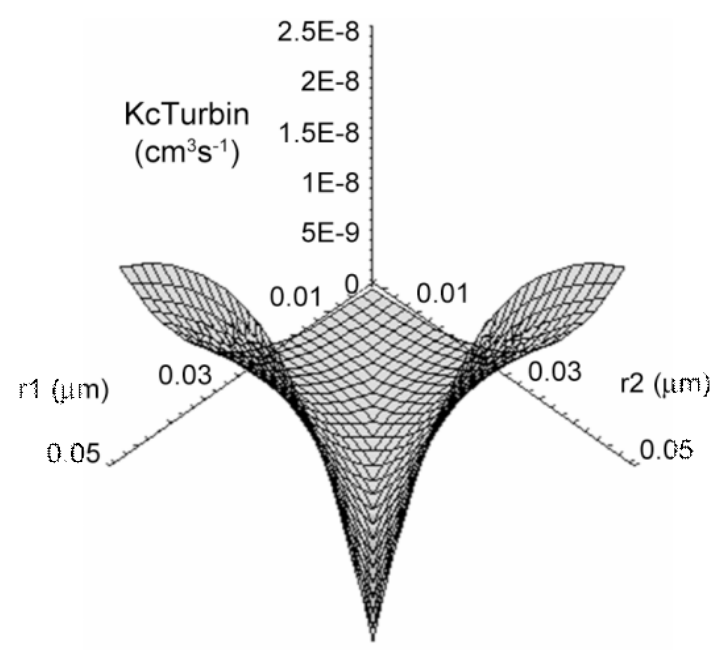

Figure 5. Radius-radius dependence of inertial shear coagulation kernel at $10 \mathrm{~atm}$ and $900 \mathrm{~K}$. 
As a consistency check, Table 1 also shows a time-scale relevant to a $5 \mathrm{~nm}$ radius, monodisperse distribution of soot at an EI of $1 \mathrm{~g} / \mathrm{kg}$-fuel. This represents the condition in the combustor primary zone immediately after nucleation. We would expect that coagulation time-scales for this distribution would indicate that coagulation occurs within the combustor and the time-scale analysis correctly predicts this. If all the soot mass is concentrated into particles of $5 \mathrm{~nm}$ of radius, the time-scale for coagulation becomes $1 \mathrm{~ms}$, which is shorter than typical combustor residence times.

Table 1. Time-scale for coagulation process at combustor exit conditions versus typical residence time for particles.

\begin{tabular}{|l|c|c|}
\hline & $\begin{array}{c}\text { Reference } \\
\text { distribution }\end{array}$ & $\begin{array}{c}\text { Monodisperse } \\
\text { distribution at } \\
5 \mathrm{~nm} \text { of radius }\end{array}$ \\
\hline $\begin{array}{l}\text { Brownian coagulation } \\
\text { time-scale }\end{array}$ & $200 \mathrm{~ms}$ & $1 \mathrm{~ms}$ \\
\hline $\begin{array}{l}\text { Shear coagulation time- } \\
\text { scale }\end{array}$ & $500 \mathrm{~ms}$ & $20,000 \mathrm{~ms}$ \\
\hline $\begin{array}{l}\text { Inertial coagulation } \\
\text { time-scale }\end{array}$ & $\begin{array}{c}\text { similar to } \\
\text { Brownian time }\end{array}$ & $\begin{array}{c}\text { virtually } \\
\text { infinite }\end{array}$ \\
\hline $\begin{array}{l}\text { Turbofan combustor } \\
\text { flow time-scale }\end{array}$ & $5-8 \mathrm{~ms}$ & $5-8 \mathrm{~ms}$ \\
\hline $\begin{array}{l}\text { Turbofan turbine flow } \\
\text { time-scale }\end{array}$ & $2-5 \mathrm{~ms}$ & $2-5 \mathrm{~ms}$ \\
\hline
\end{tabular}

A higher-fidelity analysis further confirms the conclusions derived from the time-scale comparisons. We modified the chemical library CHEMKIN coupled with the differential equations system integrator VODE to integrate the system of equation governing the concentrations of the microphysical species as differentiated by size. For the numerical analysis, the reference distribution previously described was discretized into 45 bins, truncated at a lower-bound radius of $5 \mathrm{~nm}$, the likely minimum soot spherule size, and at the upper-bound of $500 \mathrm{~nm}$, a size at which particles are almost non existent. The results of the integration through the turbine and exhaust nozzle enable us to assess changes in the median or geometric standard deviation. Figure 6 shows the particle concentration in the 45 bins at 4 locations through the turbine. Particle growth would be shown by an increase of the median diameter, a shift to the right of the distribution peak. However, coagulation growth is so weak that the simulation shows no shift within the numerical accuracy of the code. The only effect shown is due to the gas expansion through the turbine which lowers the number density by an order of magnitude.

\section{ELECTRICAL STATE}

Assessing electrical interactions is important for two reasons. First, in order to accurately characterize downstream plume processing of particles, the electrical state at the engine exit must be defined. Second, soot charges can increase the effective value of the coagulation kernel.

To calculate an enhancement factor on the coagulation kernel, we need to estimate the non-volatile particle charge distribution as established within the combustor. Depending on the fuel type, the density of ions can be as high as 1E10-1E11 in the flame zone of the combustor [33]. Figure 7, reproduced from Ball and Howard [34], shows results from a thermoionization calculation suggesting that soot particles are positively charged at typical primary zone temperatures. However, once the soot leaves the flame front in the primary zone, electrons, which have a diffusion constant 3 orders of magnitude higher than any other charged particles present in the flow, should quickly ionize other species and disappear [35].

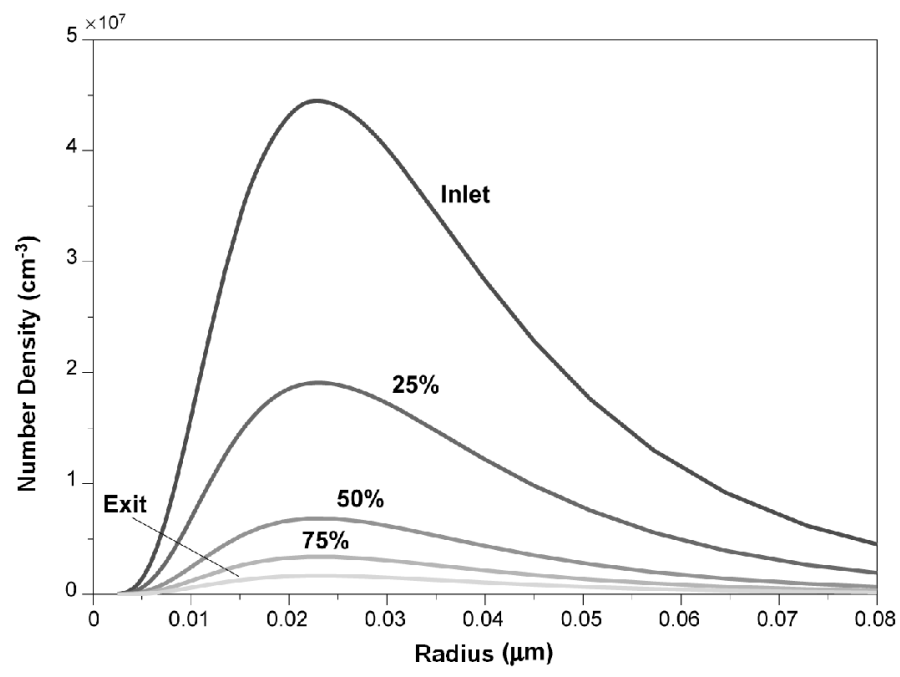

Figure 6. Simulated evolution of density versus radius through the turbine and nozzle at 5 locations.

Following the disappearance of the free electrons will be a pool of positive and negative ions that have similar diffusion constants. These ions will recombine and attach to non-volatile particulates, altering the charge distribution of the soot. As shown in Figure 8, the ion-aerosol attachment coefficient, computed according to Hoppel and Frick [36] as in Eq. (12), is of the same order of magnitude as the ion-ion recombination coefficient. Therefore the ions, which in the flame have a concentration at least three orders of magnitude larger than the soot particles, will have sufficient time to modify the charge distribution before they disappear.

$$
\mathrm{K}=\frac{4 \pi \mathrm{rD}_{\text {ion }}}{\mathrm{r} \int_{\delta}^{\infty} \frac{1}{\rho^{2}} e^{\frac{\Phi(\rho)}{k T}} d \rho+\frac{4 \mathrm{D}_{\text {ion }} r}{c b^{2}} e^{\frac{\Phi(\delta)}{k T}}}
$$

In Eq. (12), $D_{\text {ion }}$ is the ion diffusion constant, $\phi$ is the potential between the ion and the soot particle, $\lambda_{\mathrm{i}}$ is the ion mean free path of the ions, and $\delta$ is the final mean free path distance between the 2 particles just before their collision given by Eq. (13).

$$
\delta=\frac{\mathrm{r}^{3}}{\lambda_{\mathrm{i}}^{2}}\left(\frac{2}{10}\left(1-\frac{\lambda_{\mathrm{i}}}{\mathrm{r}}\right)^{5}-\frac{1}{3}\left(1+\left(\frac{\lambda_{\mathrm{i}}}{\mathrm{r}}\right)^{2}\right) \times\left(1+\frac{\lambda_{\mathrm{i}}}{\mathrm{r}}\right)^{3}+\frac{2}{15}\left(1+\left(\frac{\lambda_{\mathrm{i}}}{\mathrm{r}}\right)^{2}\right)^{\frac{5}{2}}\right)
$$




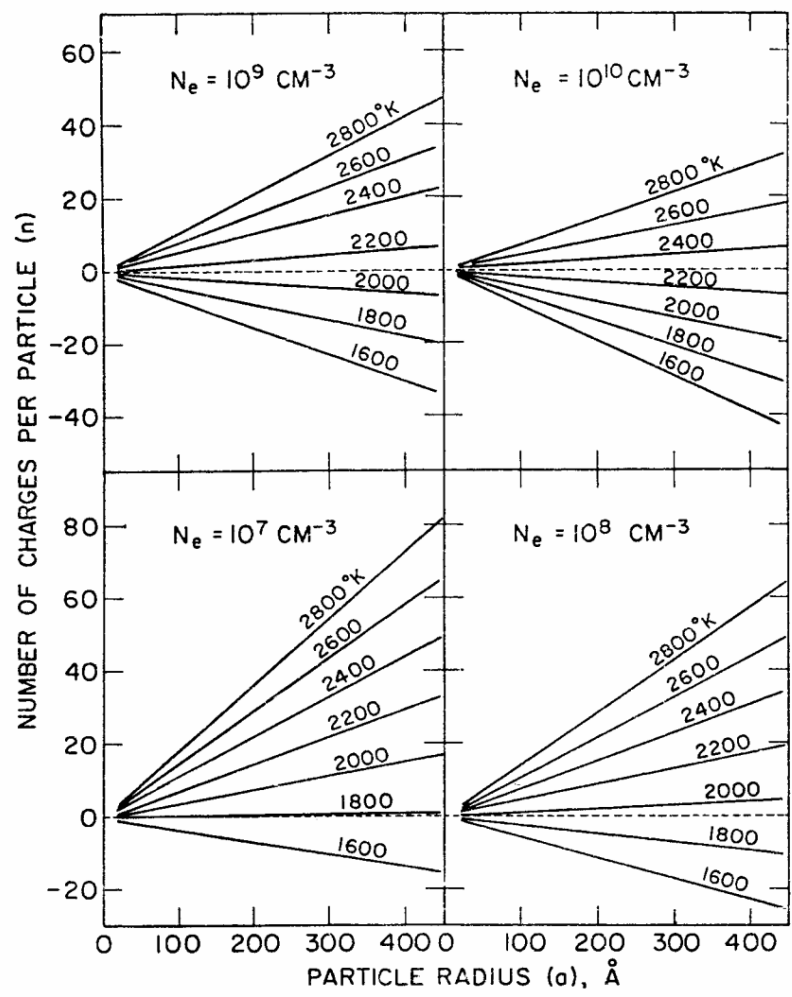

Figure 7. Equilibrium number of net charges carried by soot particles depending on radius and number of free electrons in the surronding environment. Reproduced from Ball and Howard [34]

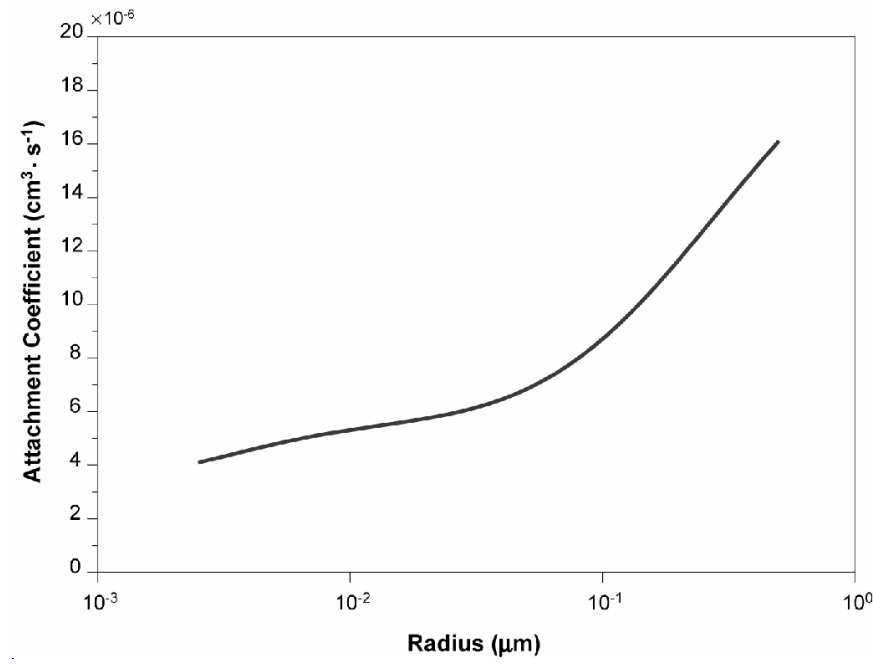

Figure 8. lons-aerosol attachment coefficient at $1250 \mathrm{~K}$ for a soot particle bearing one charge and an ion bearing a charge of opposite polarity.

In Eq. (12), $b$ is the minimum impact parameter leading to a collision, obtained by minimizing the function in Eq. (14) with respect to $\rho$.

$$
b(\rho)^{2}=\rho^{2}\left(1-\frac{2 \Phi(\rho)}{3 k T}\right)
$$

The ion diffusion constant is computed from the ion mobility. The mobility of an ion (as distinct from free electrons) is about $1 \mathrm{~cm}^{2} / \mathrm{V}$-s [33]. We assumed a mobility of $1.2 \mathrm{~cm}^{2} / \mathrm{V}-\mathrm{s}$ for our analysis and a mass of $100 \mathrm{AMU}$ for both positive and negative ions [37].

Our calculations show that because of the small radius of an ion, image and Van der Walls forces are negligible compared to Coulombic forces and hence we have neglected them. To evaluate the evolution of the charge distribution, the ion-ion recombination coefficient is parameterized over the range $1 \mathrm{E}-8$ to $1 \mathrm{E}-5 \mathrm{~cm}^{3}-\mathrm{s}^{-1}$. Experimental results suggest that the lower end of this range is more likely [36,38]. Figure 9 shows the evolution of the relative concentrations of soot particles with $-2,-1,0,+1$, and +2 charges when the initial ion concentration is $1 \mathrm{E} 11 \mathrm{~cm}^{-3}$ and the ion recombination rate is $1 \mathrm{E}-7 \mathrm{~cm}^{-3} \mathrm{~s}^{-1}$. It demonstrates rapid convergence to a steady state charge distribution of the soot particles. This result varies little over the range of ion-ion recombination rates examined, showing a difference only at the highest values. Indeed, the higher the ion-ion combination rate the less the soot charge distribution will evolve and the more dominant one polarity will be. For aircraft combustors this would lead to positively charged soot. However, our results suggest that the ions indeed have sufficient time to set the charge distribution of the soot. Moreover, the speed at which the convergence takes place indicates that the steady-state is attained within the combustor. The practical conclusion is that, if the ion concentration is sufficiently large and the attachment coefficient sufficiently fast (which are probable conditions in the combustor), then the charge distribution would be such that a significant proportion of the soot particles are carrying opposite charges. Thus, there is a potential for increased coagulation due to electrical interactions between oppositely-charged particles.

Coagulation enhancement occurs when there is an attractive potential between particles. We consider Coulomb forces, image forces (which are a correction to the Coulombic interaction), and Van der Walls forces. The Van der Walls potential between two particles separated by a distance $\rho$ is computed according to Eq. (15).

$\Phi_{v d v}(\rho)=-\frac{A_{H}}{6}\left[\frac{2 r_{1} r_{2}}{\rho^{2}-\left(r_{1}+r_{2}\right)^{2}}+\frac{2 r_{1} r_{2}}{\rho^{2}-\left(r_{1}-r_{2}\right)^{2}}+\ln \left(\frac{\rho^{2}-\left(r_{1}+r_{2}\right)^{2}}{\rho^{2}-\left(r_{1}-r_{2}\right)^{2}}\right)\right]$

In Eq. (15), $A_{H}$ is the Hamaker constant with a value of $5 \mathrm{E}-20 \mathrm{~J}$ $[39,40]$. The sum of the Coulombic and image forces is computed as given by Maxwell [41] in Eq. (16). In Eq. (16), $\varepsilon_{\mathrm{r}}$ is the relative permittivity of the soot particle taken as 5.5 [42].

$\Phi_{C}(\rho)=-\frac{q^{2}}{8 \pi \varepsilon_{0}} \frac{\varepsilon_{r}-1}{\varepsilon_{r}+1}\left(\left(p_{11}-\frac{1}{r_{1}}\right) q_{1}^{2}+2 p_{12} q_{1} q_{2}+\left(p_{22}-\frac{1}{r_{2}}\right) q_{2}^{2}\right)$

$p_{i i}=\frac{b_{i j}}{b_{i i} b_{j j}-b_{i j}{ }^{2}}, p_{i j}=-\frac{b_{i j}}{b_{i i} b_{j j}-b_{i j}{ }^{2}}$

$b_{i i}=r_{i}\left(1-\eta_{i j}\right) \sum_{m=0}^{\infty}\left[\frac{\theta^{\mathrm{m}}}{1-\eta_{\mathrm{ij}} \theta^{2 m}}\right], b_{i j}=-\frac{r_{i} r_{j}}{r}\left(1-\theta^{2}\right) \sum_{m=0}^{\infty}\left[\frac{\theta^{\mathrm{m}}}{1-\theta^{2 m+2}}\right]$ 
$\eta_{i j}=\left[\frac{r_{i}+\theta r_{j}}{\rho}\right]^{2}, \theta=\gamma-\sqrt{\gamma^{2}-1}, \gamma=\frac{\rho^{2}-r_{i}^{2}-r_{j}^{2}}{2 r_{i} r_{j}}$

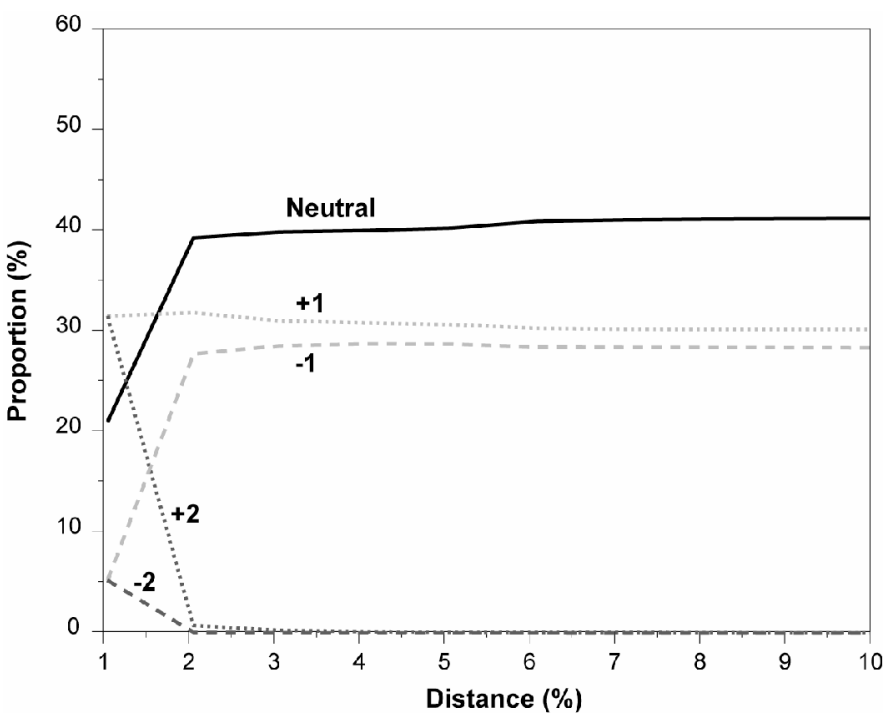

Figure 9. Evolution of the proportion of soot particles bearing $-2,-1,0,+1$, and +2 charges in the turbine starting from an arbitrary (here positive) charge distribution with an ion concentration of $1.10^{11} \mathrm{~cm}^{-3}$ and an ion recombination rate of $1.10^{-7} \mathrm{~cm}^{-3} \mathrm{~s}^{-1}$.

As with the previous consideration of the initial soot charge distribution, the enhancement to the kernel is represented as an increase in the minimum impact parameter leading to a collision, given in Eq. (14). Equation (17) is the revised kernel, including enhancement.

$$
K_{c_{b r}}=\frac{4 \pi\left(r_{1}+r_{2}\right)\left(D_{1}+D_{2}\right)}{\frac{r_{1}+r_{2}}{r_{1}+r_{2}+\sqrt{\delta_{1}^{2}+\delta_{2}^{2}}}+\frac{4\left(D_{1}+D_{2}\right)}{\sqrt{c_{1}^{2}+c_{2}^{2}} \frac{b^{2}}{\left(r_{1}+r_{2}\right)^{2}}\left(r_{1}+r_{2}\right)}}
$$

The enhancement to the kernel, i.e. the factor by which the kernel is increased when the electrical state of the particles is considered, is plotted on Figure 10 as a function of the radius of the 2 colliding particles. It shows that due to the high temperature and the relatively large size of the soot particles, the enhancement factor will remain of the order of one, hence having only a negligible effect on the coagulation. Integration of the soot distribution using the higher fidelity microphysical tool confirms the lack of growth through the turbine and exhaust nozzle for the range of conditions investigated.

\section{ROLE OF HYDROCARBONS IN ALTERING SOOT PROPERTIES}

As a final step, we briefly consider the potential for hydrocarbons (HC) to play a role in altering particle properties. Emission indices for unburned HCs can be of the same order of magnitude as the non-volatile particulate EI [43]. Thus, if condensa- tion occurs, it could modify the particle mass and hence size distribution. Analyses of plume measurements have, however, suggested the presence of $\mathrm{HC}$ nucleation in the plume $[2,23,44,45]$. However, saturation vapor pressures of these gaseous emissions are quite high under the temperature and pressure conditions experienced in the turbine flow. Using the Antoine's Law coefficients reported in [46] a few examples are computed and listed in Table 2 for HC species that might be found at the combustor exit [47]. Gas phase species at the combustor exit include organics such as small hydrocarbons and aldehydes, aromatics and substituted aromatics, and to a lesser extent, larger hydrocarbons.

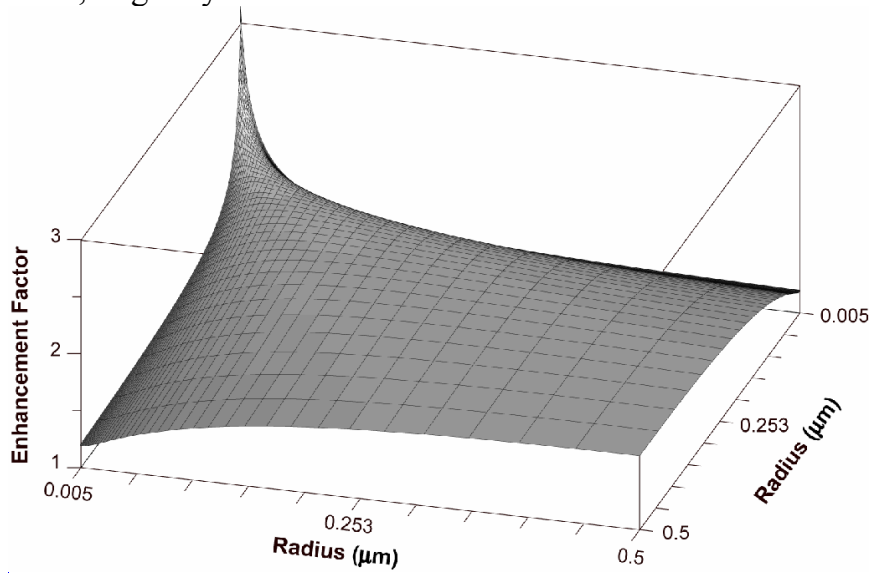

Figure 10. Enhancement factor at $1250 \mathrm{~K}$ between two particles bearing -1 and +1 charge respectively.

Table 2. Saturation pressures of some species at temperature given in parenthesis.

\begin{tabular}{|c|c|c|c|}
\hline $\begin{array}{c}\text { Heptadecane } \\
(500 \mathrm{~K})\end{array}$ & $\begin{array}{c}\text { 1-decene } \\
(440 \mathrm{~K})\end{array}$ & $\begin{array}{c}\text { 1-methyl- } \\
\text { naphthalene } \\
(500 \mathrm{~K})\end{array}$ & $\begin{array}{c}\text { Benzaldehyde } \\
(440 \mathrm{~K})\end{array}$ \\
\hline $0.15 \mathrm{~atm}$ & $0.91 \mathrm{~atm}$ & $0.67 \mathrm{~atm}$ & $0.74 \mathrm{~atm}$ \\
\hline
\end{tabular}

To our knowledge, no existing measurements at the engine exit detail the speciation of the hydrocarbons with carbon number higher than 17. In general, however, the saturation vapor pressures for the conditions examined suggest that condensation of hydrocarbons in the engine or even the near-field plume is not expected. Plume measurements may instead point to other organic emissions such as droplets of engine lubricating oil or other high carbon number compounds.

This discussion of condensation does not address the gasto-particle conversion in the exhaust flow after it exits the engine or as an exhaust sample is captured by a measurement probe and transported to a measurement instrument where temperatures and pressures may change dramatically. An additional effect not addressed here is the stabilization of hydrocarbon monolayers on the surface of the soot, which can be enhanced in the presence of (positive) charges [44]. This particular kind of deposition could potentially lead to a growth of the particle even at sub-saturated conditions. In the absence of charges, monolayers only influence the chemical properties of the nonvolatile particulate without modifying the microphysical properties. 


\section{SUMMARY}

This paper has considered the post-combustion evolution of soot properties within an aircraft engine through coagulation as potentially enhanced by electrical interactions. No process was identified that would lead to a change in soot size or charge distribution through the turbine and nozzle of the engine. The formation and initial evolution of the soot happens in the combustor. Cooling and dilution through the combustor dilution zone, turbine, and exhaust nozzle essentially freezes the properties of the non-volatile particulate matter prior to emission.

Thus, we conclude that combustor exit measurements are representative of engine exit measurements, and that changes in size distribution measured in recent sampling programs [1,2] are likely related to changes in experimental conditions, including variance in engine operating conditions, or additional processing through the measurement apparatus. It should be emphasized that these results are relevant only to the non-volatile particulate. Gas phase species do evolve significantly through the post-combustion gas path.

\section{ACKNOWLEDGMENTS}

The authors would like to acknowledge the funding provided by the UMR Center of Excellence for Aerospace Propulsion Particulate Emissions Reduction.

\section{REFERENCES}

[1] Whitefield, P., D.E. Hagen, K. Brundish, A.R. Clague, C.W. Wilson, R.C. Miake-Lye, R.C. Brown, J.

Wormhoudt, S.P. Lukachko, A.T. Chobot, C.K. Yam, and I.A. Waitz, 2002, "NASA/QinetiQ Collaborative Program, Final Report," NASA CR-2002-211900, NASA Glenn Research Center, U.S. National Aeronautics and Space Administration, Cleveland, Ohio.

[2] Petzold, A., M. Fiebig, L. Fritzsche, C. Stein, U. Schumann, C.W. Wilson, C.D. Hurley, F. Arnold, E. Katragkou, U. Baltensperger, M. Gysel, S. Nyeki, R. Hitzenberger, H. Giebl, K.J. Hughes, R. Kurtenbach, P. Weisen, P. Madden, H. Puxbaum, S. Vrchoticky, and C. Wahl, 2003, Particle emissions from aircraft engines, An overview of the European project PartEmis, European Conference on Aviation, Atmosphere, and Climate (AAC), Proceedings of an International Conference, European Commission, Friedrichshafen, Germany, pp. 41-51.

[3] Intergovernmental Panel on Climate Change, IPCC, 1999, "Aviation and the global atmosphere: A special report of the Intergovernmental Panel on Climate Change," J.E. Penner, D.H. Lister, D.J. Griggs, D.J. Dokken, and M. McFarland, eds., Cambridge University Press, Cambridge, UK.

[4] Schumann, U., F. Arnold, R. Busen, J. Curtius, B. Karcher, A. Kiendler, A. Petzold, H. Schlager, F. Schroder, and K.H. Wohlfrom, 2002, "Influence of fuel sulfur on the composition of aircraft exhaust plumes: The experiments SULFUR 1-7," Journal of Geophysical ResearchAtmospheres, 107(D15).

[5] Travis, D.J., A.M. Carleton, and R.G. Lauritsen, 2002, "Climatology: Contrails reduce daily temperature range A brief interval when the skies were clear of jets unmasked an effect on climate," Nature, 418(6898), pp. 601-601.
[6] Anderson, B.E., W.R. Cofer, J. Crawford, G.L. Gregory, S.A. Vay, K.E. Brunke, Y. Kondo, M. Koike, H. Schlager, S.L. Baughcum, E. Jensen, Y.J. Zhao, and K. Kita, 1999, "An assessment of aircraft as a source of particles to the upper troposphere," Geophysical Research Letters, 26(20), pp. 3069-3072.

[7] Schröder, F., B. Karcher, C. Duroure, J. Strom, A. Petzold, J.F. Gayet, B. Strauss, P. Wendling, and S. Borrmann, 2000, "On the transition of contrails into cirrus clouds," Journal of the Atmospheric Sciences, 57(4), pp. 464-480.

[8] Marquart, S. and B. Mayer, 2002, "Towards a reliable GCM estimation of contrail radiative forcing," Geophysical Research Letters, 29(8).

[9] Marquart, S., M. Ponater, F. Mager, and R. Sausen, 2003, "Future development of contrail cover, optical depth, and radiative forcing: Impacts of increasing air traffic and climate change," Journal of Climate, 16(17), pp. 28902904.

[10] Meyer, R., H. Mannstein, R. Meerkotter, U. Schumann, and P. Wendling, 2002, "Regional radiative forcing by line-shaped contrails derived from satellite data," Journal of Geophysical Research-Atmospheres, 107(D10).

[11] Minnis, P., J.K. Ayers, R. Palikonda, and D. Phan, 2004, "Contrails, cirrus trends, and climate," Journal of Climate, 17(8), pp. 1671-1685.

[12] U.S. Federal Aviation Administration, FAA, 2003, "Select resource materials and annotated bibliography on the topic of hazardous air pollutants (HAPs) associated with aircraft, airports, and aviation," Federal Aviation Administration, Office of Environment and Energy, Prepared by URS Corporation, Washington, D.C.

[13] Brown, R.C., M.R. Anderson, R.C. MiakeLye, C.E. Kolb, A.A. Sorokin, and Y.Y. Buriko, 1996, "Aircraft exhaust sulfur emissions," Geophysical Research Letters, 23(24), pp. 3603-3606.

[14] Lukachko, S.P., I.A. Waitz, R.C. Miake-Lye, R.C. Brown, and M.R. Anderson, 1998, "Production of sulfate aerosol precursors in the turbine and exhaust nozzle of an aircraft engine," Journal of Geophysical Research-Atmospheres, 103(D13), pp. 16159-16174.

[15] Miake-Lye, R.C., M. Martinez-Sanchez, R.C. Brown, and C.E. Kolb, 1993, "Plume and Wake Dynamics, Mixing, and Chemistry Behind a High-Speed Civil Transport Aircraft," Journal of Aircraft, 30(4), pp. 467-479.

[16] Starik, A.M., A.M. Savel'ev, N.S. Titova, and U. Schumann, 2002, "Modeling of sulfur gases and chemiions in aircraft engines," Aerospace Science and Technology, 6 (1), pp. 63-81.

[17] Tremmel, H.G. and U. Schumann, 1999, "Model simulations of fuel sulfur conversion efficiencies in an aircraft engine: Dependence on reaction rate constants and initial species mixing ratios," Aerospace Science and Technology, 3(7), pp. 417-430.

[18] Wilson, C.W., A.R. Clague, M. Pourkashanian, and L. Ma, 2004, "Chemical kinetic modeling of the evolution of gaseous aerosol precursors within a gas turbine engine," GT2004-53704, ASME Turbo Expo 2004, American Society of Mechanical Engineers, Vienna, Austria. 
[19] Lukachko, S.P., I.A. Waitz, R.C. Miake-Lye, and R.C. Brown, 2005, "Engine design and operational impacts on aircraft particulate matter precursor emissions," GT200569112, ASME Turbo Expo 2005, American Society of Mechanical Engineers, Reno-Tahoe, Nevada.

[20] Konopka, P., U. Schumann, H. Schlager, D. Hagen, P. Whitefield, and J. Ovarlez, 1997, "Particulate emissions of commercial jet aircraft under cruise conditions, Report 91," Institut für Physik der Atmosphäre, eds., DLR

[21] Schumann, U., H. Schlager, F. Arnold, J. Ovarlez, H. Kelder, Ø. Hov, G. Hayman, I.S.A. Isaksen, J. Staehelin, and P.D. Whitefield, 2000, "Pollution from aircraft emissions in the North Atlantic flight corridor: Overview on the POLINAT projects," Journal of Geophysical Research-Atmospheres, 105(D3), pp. 3605-3631.

[22] Anderson, B.E., W.R. Cofer, D.R. Bagwell, J.W. Barrick, C.H. Hudgins, and K.E. Brunke, 1998, "Airborne observations of aircraft aerosol emissions I: Total nonvolatile particle emission indices," Geophysical Research Letters, 25(10), pp. 1689-1692.

[23] Brock, C.A., F. Schroder, B. Karcher, A. Petzold, R. Busen, and M. Fiebig, 2000, "Ultrafine particle size distributions measured in aircraft exhaust plumes," Journal of Geophysical Research-Atmospheres, 105(D21), pp. 26555-26567.

[24] Hagen, D., P. Whitefield, J. Paladino, M. Trueblood, and H. Lilenfeld, 1998, "Particulate sizing and emission indices for a jet engine exhaust sampled at cruise," Geophysical Research Letters, 25(10), pp. 1681-1684.

[25] Miake-Lye, R.C., B.E. Anderson, W.R. Cofer, H.A. Wallio, G.D. Nowicki, J.O. Ballenthin, D.E. Hunton, W.B. Knighton, T.M. Miller, J.V. Seeley, and A.A. Viggiano,

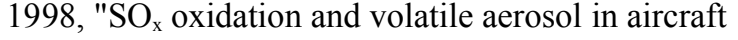
exhaust plumes depend on fuel sulfur content," Geophysical Research Letters, 25(10), pp. 1677-1680.

[26] Pueschel, R.F., S. Verma, G.V. Ferry, S.D. Howard, S. Vay, S.A. Kinne, J. Goodman, and A.W. Strawa, 1998,"Sulfuric acid and soot particle formation in aircraft exhaust," Geophysical Research Letters, 25(10), pp. 1685-1688.

[27] Anderson, B.E., W.R. Cofer, J.D. Barrick, D.R. Bagwell, and C.H. Hudgins, 1998, "Airborne observations of aircraft aerosol emissions II: Factors controlling volatile particle production," Geophysical Research Letters, 25 (10), pp. 1693-1696.

[28] Fuchs, N., 1964, The mechanics of aerosols, Dover, Mineola, New York.

[29] Seinfeld, J.H. and S.N. Pandis, 1997, Atmospheric chemistry and physics, Wiley-Interscience.

[30] Saffman, P.G. and J.S. Turner, 1955, "On the collision of drops in turbulent clouds," Journal of Fluid Mechanics, 1.

[31] Goebel, S.G., N. Abuaf, J.A. Lovett, and C.-P. Lee, 1993, Measurement of combustor velocity and turbulence profiles, ASME 93-GT-228, Twelfth International Symposium on Combustion, Pittsburg, Pennsylvania

[32] Pruppacher, H.R. and J.D. Klett, 1978, Microphysics of clouds and precipitation, D. Reidel Publishing Company, Dordrecht, Holland.

[33] Fialkov, A.B., 1997, "Investigations on ions in flames," Progress in Energy and Combustion Science, 23, pp. 399528.
[34] Ball, R.T. and J.B. Howard, 1971, Electric charge of carbon particles in flames, Thirteenth International Symposium on Combustion, Combustion Institute, Pittsburg, Pennsylvania, pp. 353-362.

[35] Sorokin, A. and F. Arnold, 2004, "Electrically charged small soot particles in the exhaust of an aircraft gasturbine engine combustor: comparison of model and experiment," Atmospheric Environment, 38(17), pp. 26112618.

[36] Hoppel, W.A. and G.M. Frick, 1986, "Ion-aerosol attachment coefficient and the steady-sate charge distribution on aerosol in bipolar ion environment," Aerosol Science and Technology, 5, pp. 1-21.

[37] Haverkamp, H., S. Wilhelm, A. Sorokin, and F. Arnold, 2004, "Positive and negative ion measurements in jet aircraft engine exhaust: concentrations, sizes and implications for aerosol formation," Atmospheric Environment, 38(18), pp. 2879-2884.

[38] Arnold, F., A. Kiendler, V. Wiedemer, S. Aberle, T. Stilp, and R. Busen, 2000, "Chemiion concentration measurements in jet engine exhaust at the ground: Implications for ion chemistry and aerosol formation in the wake of a jet aircraft," Geophysical Research Letters, 27 (12), pp. 1723-1726.

[39] Howard, J.B., B.C. Wersborg, and G.C. Williams, 1973, Coagulation of Carbon Particles in Premixed Flame, Faraday Symposium of the Chemical Society, Chemical Society, pp. 109-119.

[40] Mick, H.J., A. Hospital, and P. Roth, 1991, "Computer simulation of soot particle coagulation in low pressure flames," Journal of Aerosol Science, 22(7), pp. 831-841.

[41] Maxwell, J.C., 1954, A treatise on electricity and magnetism, Dover, New York, New York.

[42] Howard, J.B., 1969, On the Mechanism of Carbon Formation in Flames, Twelfth international symposium on combustion, Combustion Institute, Pittsburg, PA, pp. 877887.

[43] ICAO, 1995, "Engine exhaust emissions data bank, 1st edition with amendments," ICAO-9646-AN/943, International Civil Aviation Organization, Montreal, Canada.

[44] Yu, F.Q., R.P. Turco, and B. Karcher, 1999, "The possible role of organics in the formation and evolution of ultrafine aircraft particles," Journal of Geophysical ResearchAtmospheres, 104(D4), pp. 4079-4087.

[45] Karcher, B., 1998, "Physicochemistry of aircraft-generated liquid aerosols, soot, and ice particles - 1, Model description," Journal of Geophysical ResearchAtmospheres, 103(D14), pp. 17111-17128.

[46] U.S. National Institute of Standards and Technology, NIST, 2003, NIST Chemistry WebBook: NIST Standard Reference Database Number 69, W.G. Mallard, eds., Data available online at http://webbook.nist.gov/chemistry, U.S. Department of Commerce.

[47] Spicer, C.W., M.W. Holdren, R.M. Riggin, and T.F. Lyon, 1994, "Chemical-Composition and Photochemical Reactivity of Exhaust from Aircraft Turbine-Engines," Annales Geophysicae-Atmospheres Hydrospheres and Space Sciences, 12(10-11), pp. 944-955. 